\title{
Correction to: Predictors of outcomes after arthroscopic transosseous equivalent rotator cuff repair in 155 cases: a propensity score weighted analysis of knotted and knotless self-reinforcing repair techniques at a minimum of 2 years
}

Peter J. Millett ${ }^{1,2} \cdot$ Chris Espinoza $^{1,2} \cdot$ Marilee P. Horan ${ }^{1} \cdot$ Charles P. Ho $^{1,2}$.

Ryan J. Warth ${ }^{1}$ - Grant J. Dornan ${ }^{1}$ J. Christoph Katthagen ${ }^{1,3}$

Published online: 23 October 2017

(C) Springer-Verlag GmbH Germany 2017

Correction to: Arch Orthop Trauma Surg (2017)

137:1399-1408

DOI 10.1007/s00402-017-2750-7

The author claims that his name is incorrectly listed on PubMed. It seems, that the first and last name have been mixed up.

Correct first name is: J. Christoph (on PubMed: J.).

Correct last name is: Katthagen (on PubMed: Christoph Katthagen).

On SpringerLink the name is listed correctly, but on PubMed he is listed as Christoph Katthagen J.

The online version of the original article can be found under doi:10.1007/s00402-017-2750-7.

Peter J. Millett

drmillett@thesteadmanclinic.com

1 Steadman Philippon Research Institute, Center for Outcomes-Based Orthopaedic Research (COOR), 181 West Meadow Drive, Suite 1000, Vail, CO 81657, USA

2 The Steadman Clinic, 181 West Meadow Drive, Suite 400, Vail, CO 81657, USA

3 Department of Trauma, Hand and Reconstructive Surgery, University Hospital Münster, Münster, Germany 